is greater than the separation of the curves for $2 \mathrm{~F}$ and $3 \mathrm{~F}$. In terms of information integration constructs, it may be assumed that the weight or influence of a given feedback presentation has two nonadditive components, a serial component related to study trial number and an information-value component which diminishes with number of prior feedback presentations.

Further work is needed to solidify and interpret the findings presented here for verbal discrimination. In addition, the methodology described in this report may prove useful in a variety of learning tasks. Applications could include any outcome variable manipulated factorially over trials. The serial analyses illustrated here would show the extent to which the effects of these variables change over successive presentations.

\section{REFERENCES}

Anderson, N. H. Information integration theory: A brief survey.
Technical Report No. 24, Center for Human Information Processing, University of California, San Diego, April 1972.

Friedman, M. P., Carterette, E. C., \& Anderson, N. H. Long-term probability learning with a random schedule of reinforcement. Journal of Experimental Psychology, 1968, 78, 442-455.

Levin, I. P., Dulberg, C. S., Dooley, J. F., \& Hinrichs, J. V. Sequential dependencies in single-item and multiple-item probability learning. Journal of Experimental Psychology, $1972,93,262-267$.

Slovic, P., \& Lichtenstein, S. Comparison of Bayesian and regression approaches to the study of information processing in judgement. Organizational Behavior and Human Performance, 1971, 6, 649-744.

\section{NOTE}

1. Details of the procedure can be gotten by writing the first author. Briefly, on test trials, each of 16 pairs of low-frequency words was presented on a slide for 1.0 sec. During this interval, $S$ responded by pressing a button corresponding to the right-left position of his response choice. Position of a word within a pair and position of a pair within the list were varied over trials. On a study trial, the correct response for each of eight pairs was presented for $1.0 \mathrm{sec}$

(Received for publication March 22, 1973.)

\title{
Cue utilization as a function of monetary incentive and learning efficiency*
}

\author{
JEROME S. COHEN, GABOR A. TELEGDY \\ JEAN PAUL LAROCHE, and YAAKOV GETZ \\ University of Windsor, Windsor 11, Ontario, Canada
}

Different levels of monetary incentive, high (\$2.00), moderate $(\$ 0.50)$, or no reward, during either initial learning or testing conditions did not affect range of cue utilization in Ss required to learn a redundant relevant dimension concept task. Initial learning efficiency was related to cue utilization, however. Ss making more than three errors on the original task were generally unable to employ both relevant dimensions.

According to Easterbrook (1959), cue utilization of an organism is inversely related to drive level. This relationship has been found in human Ss under various types of drive conditions, such as general anxiety level (Zaffy \& Bruning, 1966), socially induced anxiety level (Bruning, Copage, Kozuh, Young, \& Young, 1968), and thirst and shock-induced fear (Solley, 1969). Bahrick (1954) found that high monetary incentive motivation (\$1.50 maximum) interfered with incidental learning of

*The present study was supported by funds from a National Research Council of Canada grant awarded to J. S. Cohen (A 7450). The authors wish to thank R. Daly and R. Orr of the Psychology Department, University of Windsor, and Z. Veres and the Windsor Public School Board for their help and cooperation. A modified version of the present study was read at the 1972 modified version of the present study was read at the 1972
Southeastern Psychological Association Convention in Atlanta, Georgia. a redundant color cue in a serial form anticipation task. The present study was an extension of Bahrick's (1954) original study on the effects of monetary incentives on cue utilization. Ss were required to master a concept classification task under one of three levels of reward, high ( $\$ 2.00$ maximum), moderate $(\$ 0.50$ maximum, and zero (no monetary reward). Each geometric figure could be classified in one of two categories by the use of one or both redundant relevant dimensions: figure closure and orientation of lines in figure. It was predicted that lower incentives would result in greater cue utilization, i.e., the use or recognition of both redundant relevant dimensions, than the high-incentive condition. Test procedures measuring cue utilization were carried out under counterbalanced incentive conditions in order to determine learning and performance effects of the various incentive conditions. The effect of incentive levels on dimension dominance was also investigated. An auxiliary investigation concerned the relationship between acquisition rate of the initial RRC task and cue utilization.

\section{METHOD}

Subjects

Sixty-three twelfth-grade boys from one of the public secondary schools in Windsor, Ontario, were used. During the 


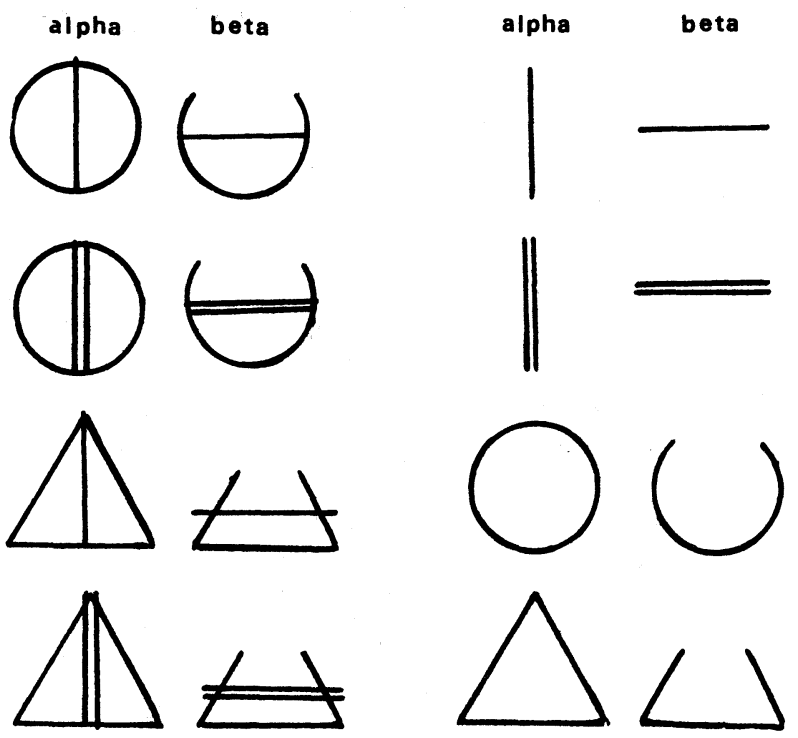

Fig. 1. Learning stimuli (Phase 1) and testing stimuli (Phase 2).

course of the experiment, five Ss had to be replaced by additional Ss due to failure to learn the original task.

\section{Apparatus}

All stimuli were presented to the Ss by a timed Kodak Carousel $35-\mathrm{mm}$ slide projector situated $10 \mathrm{ft}$ from a screen. The $\mathrm{S}$ was required to make his response to each stimulus by pressing one of two labeled buttons directly in front of him. The S's response was indicated on a separate response light indicator panel, positioned to the side and out of view of the S. Stimuli (see Fig. 1) were either 2.5-in.-diam circles or 2.5-in.-high equilateral triangles that had been photographed onto $35-\mathrm{mm}$ slides.

\section{Procedure}

The experiment was run in two parts: a training phase and a testing phase. In both phases, each $S$ was run individually. Standardized instructions were read to each $S$ at the beginning of each phase, explaining the nature of the tasks, the type of dimensions presented, the level of incentive, and the fact that stimulus presentation was randomized. In the first phase, Ss were required to learn to classify a series of eight stimuli into two classifications: "alpha" and "beta" (see Fig. 1). The stimuli contained two irrelevant dimensions (shape and number of lines) and two relevant dimensions (figure closure and line orientation) that could be utilized in solving the task. Each stimulus was presented by the projector for $8 \mathrm{sec}$ and was followed by the next slide indicating the correct answer for $8 \mathrm{sec}$. For each correct response the $S$ made, the $E$ placed a blue poker chip in front of him. For each incorrect response he made, the $E$ removed all poker chips that had been previously earned. Poker chip presentation and removal were carried out only during the slide presentation of the correct answer. This portion of the experiment was completed when the $S$ had either earned 20 chips in succession or had failed to do so in 120 stimulus presentation trials.

Each $S$ was placed into one of three incentive groups: high (HI), moderate (MOD), or nothing (0). In the HI group, each S was told that each poker chip was worth $\$ 0.10$ and that he could receive as much as $\$ 2.00$. For the MOD group, Ss were told that each chip was worth $\$ 0.025$ and that they could thus earn a maximum of $\$ 0.50$. In the 0 group, collection of chips did not yield any money. All money was paid at the end of this phase.

All eight stimuli were presented every 8 trials, up to 120 trials. The presentation of the stimuli was randomized so that no classification was repeated more than twice in succession.

The second phase constituted a test to determine what dimensions the $\mathrm{S}$ used in solving the original training task. A similar procedure was employed in this task, except that a series of stimuli containing only one attribute of each of the four dimensions was presented (see Fig. 1) for classification. Although no poker chips or correct answers were given in this part of the study, the $S$ had been informed that previous learning of the first part would help him here. Only Ss that had met acquisition criterion in the first part were allowed to continue with this phase.

In this phase, there were eight stimuli that could be classified as either "alpha" or "beta." All eight stimuli were presented every 8 trials, for a total of 48 test trials. The presentation of these stimuli was randomized so that no classification was repeated more than twice in succession. Furthermore, shapes or line attributes were never repeated more than twice in succession.

In this testing phase, Ss were reassigned randomly to either the same or different incentive groups. Therefore, within any one training incentive group of $21 \mathrm{Ss}, 7$ were reassigned to their previous incentive conditions, 7 were placed on one of the other incentive conditions, and the remaining 7 were placed in the other incentive condition. The same criterion and maximum reward as used in the training section were applied here. Thus, the 7 MOD-MOD Ss would have received the same moderate incentive in both phases, while the 7 MOD-HI and 7 MOD-0 Ss would have received the moderate incentive in the initial training but the high and low incentive, respectively, during the testing phase.

\section{RESULTS}

All groups appeared to learn the initial task within similar amounts of errors $(\overline{\mathrm{X}}=6.0$ for $\mathrm{HI}, 7.4$ for MOD, and 6.1 for 0 group). A one-way analysis of variance for acquisition errors failed to find a significant main effect for incentive level $(F=0.12, \mathrm{df}=2 / 60)$. As seen in Table 1, incentive level during initial task or testing did not appear to affect amount of cue utilization. A three-way analysis of variance (Training Incentive by Testing Incentive by Redundant Dimension Presentation, repeated measure) found a significant effect only for dimension dominance $(F=25.98$, $\mathrm{df}=1 / 54, \mathrm{p}<.01)$. Significantly fewer errors were made

Table 1

Mean Errors, Standard Deviations, and Number of Ss Utilizing Zero, One, or Two Relevant Dimensions in Testing

\begin{tabular}{|c|c|c|c|c|c|c|c|}
\hline \multirow[b]{3}{*}{$\begin{array}{l}\text { Group } \\
\mathrm{N}=7\end{array}$} & \multicolumn{4}{|c|}{ Dimension } & \multirow{2}{*}{\multicolumn{3}{|c|}{$\begin{array}{c}\text { Number } \\
\text { of Ss } \\
\text { Using }\end{array}$}} \\
\hline & \multicolumn{2}{|c|}{ Closure } & \multicolumn{2}{|c|}{ Orientation } & & & \\
\hline & $\begin{array}{l}\text { Mean } \\
\text { Error }\end{array}$ & SD & $\begin{array}{l}\text { Mean } \\
\text { Error }\end{array}$ & SD & $\begin{array}{c}1 \\
\text { Dime }\end{array}$ & & $\begin{array}{c}0 \\
\text { ions }\end{array}$ \\
\hline $\begin{array}{l}\text { HI-HI } \\
\text { HI-MOD } \\
\text { HI-O }\end{array}$ & $\begin{array}{l}2.0 \\
4.7 \\
3.6\end{array}$ & $\begin{array}{l}3.9 \\
8.7 \\
4.5\end{array}$ & $\begin{array}{l}7.1 \\
7.4 \\
5.3\end{array}$ & $\begin{array}{l}5.5 \\
8.8 \\
5.5\end{array}$ & $\begin{array}{l}3 \\
3 \\
3\end{array}$ & $\begin{array}{l}3 \\
3 \\
3\end{array}$ & $\begin{array}{l}1 \\
1 \\
1\end{array}$ \\
\hline $\begin{array}{l}\text { MOD-HI } \\
\text { MOD-MOD } \\
\text { MOD-O }\end{array}$ & $\begin{array}{l}0.4 \\
1.3 \\
3.3\end{array}$ & $\begin{array}{l}1.1 \\
3.4 \\
3.5\end{array}$ & $\begin{array}{l}8.1 \\
7.6 \\
5.6\end{array}$ & $\begin{array}{l}7.3 \\
5.3 \\
5.9\end{array}$ & $\begin{array}{l}4 \\
6 \\
1\end{array}$ & $\begin{array}{l}3 \\
1 \\
4\end{array}$ & $\overline{-}$ \\
\hline $\begin{array}{l}\mathrm{O}-\mathrm{HI} \\
\mathrm{O}-\mathrm{MOD} \\
\mathrm{O}-\mathrm{O}\end{array}$ & $\begin{array}{l}4.1 \\
1.0 \\
1.7\end{array}$ & $\begin{array}{l}5.2 \\
1.8 \\
4.1 \\
\end{array}$ & $\begin{array}{l}7.5 \\
5.1 \\
8.1 \\
\end{array}$ & $\begin{array}{l}5.8 \\
5.5 \\
8.7 \\
\end{array}$ & $\begin{array}{l}3 \\
4 \\
3\end{array}$ & $\begin{array}{l}2 \\
3 \\
3 \\
\end{array}$ & $\begin{array}{l}2 \\
\overline{1}\end{array}$ \\
\hline
\end{tabular}


on the figure closure attribute stimuli than on line orientation attribute stimuli.

Analyses of the number of Ss under each training and incentive level who recognized or utilized both dimensions also show that monetary incentive did not affect range of cue utilization. As seen in Fig. 1, during the testing phase each attribute of each of the dimensions was presented separately. Each dimension contained four attributes. Each of these attribute stimuli was presented six times throughout the testing phase. A $\mathrm{S}$ was considered to have learned the closure dimension if he made more than $50 \%$ correct responses (four or more) to each of the closure stimuli. The same criterion was applied determining the correct utilization of the orientation dimension (see Table 2).

Of the $63 \mathrm{Ss}$, only eight failed to recognize either relevant dimension correctly. No significant differences were found between groups differentiated by either training incentive or testing incentive conditions in the number of Ss using both dimensions. In each incentive-trained group of $21 \mathrm{Ss}, 9 \mathrm{HI}-, 8 \mathrm{MOD}$-, and 8 0-level Ss recognized both dimensions correctly. When only incentive level under testing condition was taken into account, $8 \mathrm{HI}, 7 \mathrm{MOD}$, and 100 out of each group of 21 Ss utilized both dimensions correctly.

It was further found that incentive level, during either training or testing conditions, did not affect the dominant dimension used by those Ss recognizing only one dimension correctly. Examination of training incentive groups found that 7 out of $8 \mathrm{HI}, 10$ out of 11 MOD, and 9 out of 100 one-dimension utilizers used the closure dimension. Similar patterns were found for the Ss under incentive levels during testing, i.e., all $10 \mathrm{HI}, 10$ out of $13 \mathrm{MOD}$, and all 60 one-dimension utilizers also recognized only the closure dimension. Binomial tests established that, within each incentive-trained or -tested group significantly more Ss used the figure closure than the line orientation as the dominant dimension $(\mathrm{p}<.05)$.

The relationship between original learning performance and cue utilization was also investigated. The original learning task, it will be recalled, contained stimuli that had two redundant relevant and two irrelevant dimensions. Since each $S$ was told before the experiment what these dimensions were, the optimum maximum amount of errors a $S$ could make before discovering one of the relevant dimensions would be three if he proceeded to test one dimension at a time. More than three errors might indicate that a $S$ could not remember which dimension had been previously rejected, had forgotten what dimensions existed in this task, or used some other less efficient learning strategy. The above assumptions provided a basis for classifying Ss as either efficient learners (making three or less errors on the original task) or inefficient learners (making more than three errors). As seen in Table 2 , a significantly larger proportion $(20$, or $87 \%)$ of the 23 inefficient learners were unable to recognize both relevant
Table 2

Number of Efficient and Inefficient Learners Utilizing One (or None) and Both Dimensions

\begin{tabular}{lcc} 
& \multicolumn{2}{l}{ Number of Dimensions } \\
\cline { 2 - 3 } Type of Learner & $\begin{array}{c}\text { One or } \\
\text { None }\end{array}$ & Both \\
\hline Efficient ( $<3$ Errors) & 18 & 22 \\
Inefficient ( $>3$ Errors) & 20 & 3 \\
\hline
\end{tabular}

dimensions $(p<.001)$. Of the 40 efficient learners, 22 , or $55 \%$, a nonsignificant proportion, displayed knowledge of both relevant dimensions. A significant association between learning efficiency and amount of cue utilization was found $\left(\chi^{2}=9.06, \mathrm{df}=1, \mathrm{p}<.01\right)$.

\section{DISCUSSION}

The present study failed to replicate findings by Bahrick (1954) that increased monetary incentive would decrease cue utilization. Although Bahrick used college students and an incidental learning task while the present study used high school students and a redundant relevant cue task, the main factor accounting for these divergent findings appears to be differences in instruction. Bahrick informed his high-incentive group (\$1.50) that he was interested in how well they would do when trying their very best. He instructed his low-incentive (0) group, however, to pay attention to the task as if they were listening to a boring lecture. The use of these two different instructions could have differentiated the incentive groups by changing task-related achievement motivation or by directly altering their field of attention. Thus, incentive levels were confounded by instructional sets to attend. In the present study, only information concerning incentives differed between the three groups during the instructions in each phase.

The present study did find a relationship between learning efficiency based on a simple hypothesis testing strategy and amount of cue utilization. Trabasso \& Bower (1968) have described such a learning strategy in the acquisition of dimension and stimulus validity. While it was clearly shown than Ss who appeared to use some other learning approach could not acquire relevancy of both redundant dimensions, a hypothesis-testing strategy did not guarantee two-cue utilization. There was a greater probability, however, that a $S$ using the hypothesis testing strategy would also be able to utilize both dimensions. These results pose a question as to whether specific learning strategies increase cue utilization or both learning characteristics are concurrent and dependent on some other learning mechanism. The data suggest that the question of cause and effect might be resolved by experiments in which one- and two-cue utilizers are taught hypothesis testing strategies between an initial and second RRC task.

\section{REFERENCES}

Bahrick, H. P. Incidental learning under two incentive conditions. Journal of Experimental Psychology, 1954, 47, 170-172.

Bruning, J. L., Capage, J. E., Kozuh, G. F., \& Young, W. E. Socially induced drive and range of cue utilization. Journal of Personality \& Social Psychology, 1968, 9, 242-244.

Easterbrook. J. A. The effect of emotion on cue utilization and the organization of behavior. Psychological Review, 1959, 66, 183-201.

Solley, C. M. Effects of stress on perceptual attention. In B. P. Rourke (Ed.), Explorations in the psychology of stress and anxiety, Don Mills: Longmans Canada, 1969. Pp. 1-14.

Trabasso, T., \& Bower, G. H. Attention in learning: Theory and research. New York: Wiley, 1968.

Zaffey. D.. \& Bruning, J. L. Drive and the range of cue utilization. Journal of Experimental Psychology, 1966, 71. 383-384.

(Received for publication March 19, 1973.) 